\title{
Simultaneous 'hotspots' and 'coldspots' of marine biodiversity and implications for global conservation
}

\author{
Andrew R. G. Price* \\ Ecology and Epidemiology Group, Department of Biological Sciences, University of Warwick, Coventry CV4 7AL, \\ United Kingdom
}

\begin{abstract}
Global and smaller-scale assessments of biodiversity typically use only 'species' measures. Using a broader set of concepts, we show that different biodiversity elements can exhibit contrasting patterns within the same environment. The Arabian Gulf, estuaries and hydrothermal vents are stressful environments having low species richness yet high $\beta$ (turnover)-diversity, and around vents taxonomic distinctness is also marked. Similarly, in the Atlantic, $\beta$-diversity of starfishes declines from the coasts to the deep sea, contrasting with patterns of species richness and taxonomic distinctness. Thus, environments can, unexpectedly, be both 'hotspots' and 'coldspots' of biodiversity. These results have major implications for international conservation programmes which use biodiversity as a major criterion for identifying priority regions. Unpicking and prioritizing biodiversity's different threads will help environmental organisations better define and target hotspot regions. Current applications of complementarity could theoretically be expanded from a regional to a global perspective, to determine areas in which biodiversity representation is maximal but concepts are not applicable to assemblage properties (e.g. taxonomic distinctness).
\end{abstract}

KEY WORDS: Species richness - $\beta$ (turnover)-diversity · Taxonomic distinctness · Arabian Gulf · Estuaries $\cdot$ Hydrothermal vents $\cdot$ Atlantic $\cdot$ Asteroids

\section{INTRODUCTION}

Comprehensive understanding of biodiversity is difficult in both ecology and conservation in view of the concept's multidimensional nature (Gray 1997, 2000, Margules \& Pressey 2000, Purvis \& Hector 2000, Warwick \& Clarke 2001). Often assessments have centred on 'species' measures such as richness (Williams et al. 1996, Reid 1998), heterogeneity diversity (relative abundance of species; Gray 2000) and endemism (Williams et al. 1996, Reid 1998), to define biodiversity hotspots. Recent concepts have included complementarity (Williams et al. 1996, Reid 1998, Margules \& Pressey 2000, Warwick \& Clarke 2001, Williams 2001)

*E-mail: andrew.price@warwick.ac.uk and taxonomic distinctiveness as measures of relatedness (Warwick \& Clarke 2001), for maximising biodiversity representation within a limited area. These approaches are commonly used in terrestrial but not marine conservation planning.

For biodiversity assessments involving different sampling methods and/or spanning multiple habitats, advantages of taxonomic distinctness and other estimates of phylogenetic or taxonomic relatedness, based on average properties (Warwick \& Clarke 2001), seem compelling. These measures can be computed from simple, even partially complete species lists (Warwick \& Clarke 1998) (i.e. low-resolution data), are relatively insensitive to disparities in sampling effort and taxonomic rigour and, additionally, may provide more intuitive/comprehensive measures of biodiversity than conventional, 'species' indices (Warwick \& Clarke 
1998, 2001, Izsak \& Price 2001). Taxonomic distinctness concepts may have particular application in global and other broadscale geographic comparisons of biodiversity and global change, particularly over large space and time scales (Warwick \& Clarke 2001). $\beta$ (turnover)-diversity, i.e. change in species composition (not richness) along a spatial dimension, is another facet of biodiversity (Gray 2000, Izsak \& Price 2001). It, too, has much conservation significance (Schlacher et al. 1998), yet has generally been neglected, particularly in marine environments (Gray 2000, Izsak \& Price 2001).

Despite attraction for conservation planning, the justification for distilling biodiversity - a complex biological attribute-to a few dimensions or even a single universally applicable index of diversity (Margules \& Pressey 2000, Purvis \& Hector 2000) is uncertain. Clearly, the stronger the intercorrelations among different measures of biodiversity, the more robust might be such an approach (Purvis \& Hector 2000). Recent reviews (Lande 1996, Gray 2000, Warwick \& Clarke 2001) indicate varying degrees of concordance among biodiversity measures, but generally not negative correlation, although this too has been observed between different simulated taxonomic distinctness measures) (Warwick \& Clarke 2001) and between species/taxon richness and endemism (Price 1982, Sheppard et al. 1992, Reid 1998).

In this paper we examine biodiversity from a much broader perspective, involving both conventional 'species' and relatedness measures involving taxonomic distinctness, as well as $\beta$-diversity. Using examples from both stressful and normal marine environments, we demonstrate contrasting patterns of biodiversity using different measures in the same environment.

\section{METHODS}

Biodiversity is assessed for 3 stressful environments (Arabian Gulf, estuaries, hydrothermal vents) at various spatial scales. The data are semi-quantitative, aggregate measures of different dimensions of overall biodiversity, i.e. all species groups for which data are available, derived from species presence/absence information (details in 'Results' and Table 1). For the Arabian Gulf, $\beta$-diversity is expressed as dissimilarity of species in different benthic biotopes/ecosystems, following cluster analysis using Ward's (1963) method. $\beta$-diversity for estuaries and hydrothermal vents is the qualitative change in species composition along a spatial gradient. Biodiversity is also determined for less stressful, normal environments, as represented by asteroids (starfishes) from different depth zones of the Atlantic (details in Table 2).

\section{RESULTS}

\section{Stressful environments}

The Arabian Gulf's biota is impoverished, with low species richness (Table 1) at both the large area/biogeographical province scale and the within samplescale for many groups, including corals, algae and echinoderms (Price 1982, Sheppard et al. 1992). This is attributed to stressful environmental conditions, including extreme sea temperatures $\left(<12\right.$ to $\left.30^{\circ} \mathrm{C}\right)$ and high salinities (40 to $60 \mathrm{ppt)} \mathrm{(Sheppard} \mathrm{et} \mathrm{al.} \mathrm{1992),}$ coupled with devastating post-Pleistocene sea-level fluctuations (Price 1982). Yet the Gulf has distinctive habitats and assemblages, and hence $\beta$-diversity is high (Fig. 1). The opposite pattern is evident for the Chagos Archipelago. The high biodiversity commonly attributed to this central Indian Ocean archipelago stems from its rich reefs (Spalding 1999) and associated biota. Coral species richness is the second highest (220 species) of 26 regions in the Indian Ocean, whereas the Gulf (62 species) is among the most species-poor regions (Sheppard 2000). But Chagos has remarkably few marine habitats (reef coral, coralline algae, sand; Price 1999), relatively constant environmental conditions, and high connectivity among sites (Price 1999, Spalding 1999); $\beta$-diversity is therefore low. Hence, is Chagos unequivocally a 'hotspot' and the Gulf a 'coldspot' of biodiversity?

Some biota in the Gulf also display high endemism (e.g. $15 \%$ ocypodid and grapsid crabs: Apel \& Türkay 1999; $12 \%$ echinoderms: Price 1982) as well as high genetic diversity (mangroves; Dodd et al. 1999). Populations with high genetic diversity theorically have greater evolutionary potential or capacity to adapt to changing environmental conditions (Roberts et al. 2002a). In the Gulf and most of the world's environments, genetic diversity is poorly understood and has not been a significant factor influencing the selection

Table 1. Biodiversity in selected stressful marine environments, showing various measures of biodiversity on ordinal scale (+: low, ++: moderate, +++: high; -: insufficiently known). SR: species richness at small and large spatial scales up to biogeographical province for the Gulf, and at smaller scales (sample species richness) for estuaries and hydrothermal vents. $\Delta^{*}$ : taxonomic distinctness determined by methods of Warwick \& Clarke (2001)

\begin{tabular}{|lcccc|}
\hline $\begin{array}{l}\text { Environment/ } \\
\text { ecosystem }\end{array}$ & \multicolumn{4}{c|}{ Element of biodiversity } \\
& SR & Endemism & $\Delta^{*}$ & $\beta$-diversity \\
\hline Arabian Gulf & + & ++ & - & +++ \\
Estuaries & + & + & - & +++ \\
Hydrothermal vents & + & +++ & +++ & +++ \\
\hline
\end{tabular}


of protected areas (Roberts et al. 2002a). In some terrestrial cases (parts of Vavilov Centres) hotspots of high plant genetic diversity (Hawkes 1999) are represented in protected area systems (IUCN 1994).

At a smaller (ecosystem) scale, other stressful environments with low species richness include estuaries (Table 1). Since biota prograde from stenohaline marine species through euryhaline species to exclusively freshwater species, there is rapid spatial species turnover over tens of kilometres or less. Hence, estuar-

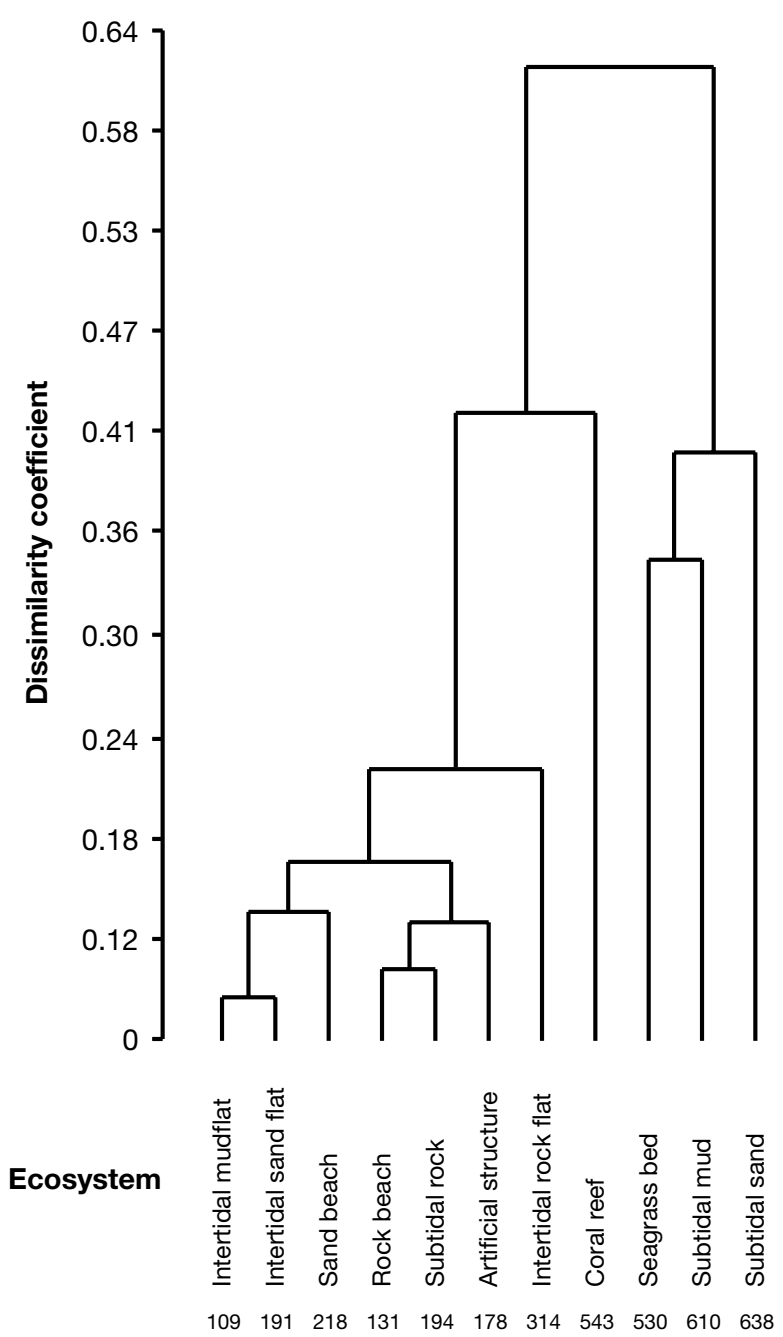

Fig. 1. Dendrogram compiled from cluster analysis of presence/absence data for benthic biotopes/ecosystems of the western Arabian Gulf (Sheppard et al. 1992) using Ward's (1963) method. At least 11 major benthic habitats and assemblages are recognised, and the species richness (as number of species) of each is indicated on abscissa (from Basson et al. 1977). Mangroves and saltmarshes, which (unusually) co-occur in this region, have been excluded as they form part of intertidal mudflats. Distinctive sub-assemblages are also evident, 2 in subtidal mud, 2 in subtidal sand (from Sheppard et al. 1992), and 6 intertidal infaunal assemblages (from McCain 1984) ies have very high $\beta$-diversity. Another example is the (sulphur-driven) hydrothermal vent assemblages (Table 1), which are small (25 to $60 \mathrm{~m}$ diameter) and comprise a highly distinctive fauna (>95\% endemism to vent fields) confined to just a few metres of the vent system (Nybakken 1997). Hence, $\beta$-diversity around vent regions is high, despite low species richness (several hundred species) compared with other deep-sea localities (Lutz \& Kennish 1993). Taxonomic distinctness is also qualitatively high, on account of the higher taxa richness (which include newly recorded/endemic taxa: 1 phylum, 1 class, 3 orders, more than 20 families and 50 genera; Tunnicliffe 1992).

\section{'Normal' environments illustrated using starfish depth distributions in the Atlantic}

Table 2 shows the biodiversity of Atlantic starfishes at the supra-biogeographical province (oceanic) scale, as an example of less stressful environments. $\beta$-diversity is maximal in coastal waters, lower at intermediate depths, and least in deep-ocean basins. In contrast, species richness of coastal waters and the deep sea are equivalent, and greater than at intermediate depths. However, when area differences are taken into account, there is evidence (from 2 regions) that shallow coastal waters may be more diverse than the deep sea. Overall, endemism is twice as great in the deep sea than at the coast. Taxonomic distinctness, a measure relatively uninfluenced by sampling effort, shows yet another pattern: significantly higher biodiversity at intermediate depths than in shallow waters (differences with the deep sea not being significant). Hence, within a given region, radically different biodiversity patterns can emerge from the same dataset, depending on which facet(s) are examined. A global example of this apparent incongruity is evident from comparisons between sea (ca. 15\% of recorded species, 32 of 33 phyla represented) and land (12 of 33 phyla represented) (May 1994).

\section{DISCUSSION}

This paper is not a comprehensive review of marine biodiversity determined according to different metrics, and the set of examples is necessarily limited. Further, biodiversity estimates are not all based on high-resolution data, which are generally difficult to obtain at large/oceanic scales and for remote environments. Nevertheless, the study demonstrates that environments can exhibit contrasting patterns of biodiversity depending upon which element is being measured. This ecological observation has major conservation implications. 
Table 2. Biodiversity of Atlantic Ocean starfishes by depth, showing a broad spectrum of biodiversity measures determined from comprehensive data set (Price et al. 1999). SR $\mathrm{O}_{\mathrm{O}}$ supra-biogeographical province or ocean-scale species richness. N: total number of species (after standardising for area difference and scaling to 1) for 2 adjacent comprehensively sampled and comparable regionsUK continental region (0 to $499 \mathrm{~m}$ depth) and Western European Basin/Rockall Trough (>500 m depth). $\Delta^{*}$ : taxonomic distinctness computed using methods of Warwick \& Clarke (2001). $\Delta^{* *}$ : 'quantitative' formulation of taxonomic distinctness using prevalence of each species, and \% cover or area occupied by each species (Price et al. 1999). $\beta$-diversity determined from assemblage distinctiveness by cluster analysis using Dice similarity coefficient and group average clustering method (Price et al. 1999). Using recently developed taxonomic similarity $\left(\Delta^{\mathrm{S}}\right)$ indices, mid-waters have highest $\beta$-diversity (Izsak \& Price 2001); only endemism levels for coastal waters and deep ocean could be estimated from compiled data (Price et al. 1999)

\begin{tabular}{|lcccccc|}
\hline Depth zone & \multicolumn{8}{c|}{$\begin{array}{c}\text { Element of biodiversity } \\
\end{array}$} & $\begin{array}{c}\text { Species richness } \\
\text { SR }\end{array}$ & $\mathrm{N}$ & Endemism & $\Delta^{*}$ & $\Delta^{* *}$ & $\beta$-diversity \\
\hline $\begin{array}{c}\text { Coastal } \\
(0-200 \mathrm{~m})\end{array}$ & 199 & 1 & 8 & 3.63 & $3.53-3.54$ & High \\
$\begin{array}{c}\text { Mid-waters } \\
(200-500 \mathrm{~m})\end{array}$ & $135-169$ & & & 3.71 & $3.68-3.69$ & Moderate \\
$\begin{array}{c}\text { Deep ocean } \\
(>500 \mathrm{~m})\end{array}$ & 198 & 0.74 & 16 & 3.72 & $3.71-3.72$ & Low \\
\hline
\end{tabular}

Warwick \& Clarke 2001, Williams 2001). Although no organisation appears to have used complementarity for defining priority regions for conservation at the global level, current applications for identifying locations in which biodiversity representation is maximal could theoretically be expanded from a regional perspective (Williams et al. 1996, Margules \& Pressey 2000, Warwick \& Clarke 2001, Williams 2001). It is unclear if the Chagos Archipelago and Arabian Gulf would be among such a global set of locations. Principles of complementarity could also help ensure representation of distantly related species, and hence adequate coverage of sites from different biogeographic regions. Clearly, a massive (global) database of species or other biodiversity features would be needed, but is unavailable. Further, similar patterns of complementarity among well-studied taxa are not assured (Pimm \& Lawton 1998, Williams 2001). In contrast to comple-

Attempts to counteract biodiversity erosion form the thrust of the Convention of Biological Diversity and many other programmes (Gray 1997). The Global Environment Facility (GEF) of the World Bank and UN Development Programme is the world's largest environmental initiative, with a 3 yr budget of $\$>2$ billion (Sherman \& Duda 1999; see www.gefweb.org). One of its major eligibility criteria for funding is to be 'rich in biodiversity'. In these and other programmes, assessment and conservation of hotspots to date has invariably involved very limited biodiversity concepts. But, as this paper shows, environments identified as hotspots using one measure can be coldspots when evaluated by another. This study reinforces the view that biodiversity conservation practice lags behind advancing ecological theory (Pimm \& Lawton 1998), especially for marine environments (Warwick \& Clarke 2001, Roberts et al. 2002a).

How might this discordance be addressed? For mainly practical reasons, biodiversity surrogates are clearly needed and are the way forward (Warwick \& Clarke 2001), so what approaches for biodiversity assessment and conservation might prove fruitful?

First, complementarity is a central concept for prioritizing areas in systematic conservation planning (Margules \& Pressey 2000). It determines the extent to which a new area contributes otherwise unrepresented features (evolutionary characters, species richness and/or restricted range, habitats) to another area or system of areas (Williams et al. 1996, Margules \& Pressey 2000, mentarity and other measures of taxonomic distinctiveness, which focus on individual species or features, taxonomic distinctness is an assemblage property (Warwick \& Clarke 2001). It measures features of its overall taxonomic spread, to which the concept of complementarity is not applicable (Warwick \& Clarke 2001). It finds greater application in marine biodiversity assessment, while the use of complementarity and taxonomic distinctiveness has been confined mainly to terrestrial conservation (Warwick \& Clarke 2001).

Second, following from the above, biodiversity must be disaggregated into its constituent elements, including commonly neglected aspects such as taxonomic distinctness and $\beta$-diversity, whose functional role is still unclear. More generally, links between biodiversity and ecosystem services require urgent research attention (Pimm et al. 2001). In the absence of comprehensive assessments, representation of all ecosystems/ habitats serves as a proxy for encompassing areas of high species richness (Roberts et al. 1999) and $\beta$-diversity. However, different biogeographical regions cannot be compared directly using this approach.

Third, biodiversity needs to be assessed at different spatial scales: point, sample, large area and biogeographical province, the last 3 scales equating approximately to $\alpha, \gamma$ and $\varepsilon$-diversity as used in earlier literature (Gray 2000). IUCN (The World Conservation Union) has recommended protecting $\geq 10 \%$ of every biogeographic region (Reid 1998). Broadscale protection is urgently required, irrespective of whether con- 
servation attention is directed at species or ecosystems/assemblages (Roberts et al. 2002a,b). The present analysis underscores the need for the protection bar to be set higher: $10 \%$ would be barely adequate to incorporate the full spectrum of biodiversity even using the present, simplistic concepts of diversity. Applying biodiversity criteria in the broader sense set out in this paper will almost certainly require more area to be protected (see also Roberts et al. 2002b).

There is urgent need for environment programmes to expand the range of biodiversity concepts and measures that they use. Retaining a straightforward focus on richness/endemism and other species measures may leave aspects of diversity inadequately protected. Equally, species-poor systems may need greater conservation effort in order to avoid the loss of essential ecosystem services. Elucidating and prioritizing biodiversity's different facets should help ecologists better define, and organisations better target, high-priority regions for protection.

Acknowledgements. The author thanks C. R. C. Sheppard and C. R. Margules for comments on an early draft of the manuscript. The criticisms and suggestions of the referees are also acknowledged with thanks.

\section{LITERATURE CITED}

Apel M, Türkay M (1999) Taxonomic composition, distribution and zoogeographic relationships of the grapsid and ocypodid crab fauna of intertidal soft bottoms in the Arabian Gulf. Estuar Coast Shelf Sci 49 (Suppl A):131-142

Basson PW, Burchard JE, Hardy JT, Price ARG (1977) Biotopes of the Western Arabian Gulf: marine life and environments of Saudi Arabia. ARAMCO, Dhahran, Saudi Arabia

Dodd RS, Blasco F, Rafii Z, Torquebiau E (1999) Mangroves of the United Arab Emirates: ecotypic diversity in cuticular waxes at the bioclimatic extreme. Aquat Bot 63:291-304

Gray JS (1997) Marine biodiversity: patterns, threats and conservation needs. Biodivers Conserv 6:153-175

Gray JS (2000) The measurement of marine species diversity, with an application to the benthic fauna of the Norwegian continental shelf. J Exp Mar Biol Ecol 250:23-49

Hawkes JG (1999) The evidence for the extent of N.I. Vavilov's new world Andean centres of cultivated plant origins. Genet Resour Crop Evol 46:163-168

IUCN (The World Conservation Union) (1994) United Nations list of national parks and protected areas. WCMC and CNPPA, IUCN, Gland, Switzerland, Cambridge, UK

Izsak C, Price ARG (2001) Measuring $\beta$-diversity using a taxonomic similarity index, and its relation to spatial scale. Mar Ecol Prog Ser 215:69-77

Lande R (1996) Statistics and partitioning of species diversity, and similarity among multiple species communities. Oikos 76:5-13

Lutz R, Kennish M (1993) Ecology of deep-sea hydrothermal vent communities - a review. Rev Geophys 31:211-242

Margules CR, Pressey RL (2000) Systematic conservation planning. Nature 405:243-253

May RM (1994) Conceptual aspects of the quantification of the extent of biological diversity. Philos Trans R Soc Lond B Biol Sci 345:13-20

McCain JC (1984) Marine ecology of Saudi Arabia. The intertidal infauna of sandy beaches in the Northern Area, Arabian Gulf, Saudi Arabia. Fauna Saudi Arabia 6:53-78

Nybakken JW (1997) Marine biology: an ecological approach. Addison-Wesley, Reading

Pimm SL, Lawton JH (1998) Planning for biodiversity. Science 27:2068-2069

Pimm SL et al. (>30 co-authors) (2001) Can we defy nature's end? Science 293:2207-2208

Price ARG (1982) Echinoderms of Saudi Arabia: comparison between echinoderm faunas of Arabian Gulf, SE Arabia, Red Sea and Gulfs of Aqaba and Suez. Fauna Saudi Arabia 4:3-21

Price ARG (1999) Broadscale coastal environmental assessment of the Chagos Archipelago. Linn Soc Occas Pap 2: 285-296

Price ARG, Keeling MJ, O'Callaghan CJ (1999) Ocean-scale patterns of 'biodiversity' of Atlantic asteroids determined from taxonomic distinctness and other measures. Biol J Linn Soc 66:187-203.

Purvis A, Hector A (2000) Getting the measure of biodiversity. Nature 405:212-219

Reid WV (1998) Biodiversity hotspots. Trends Ecol Evol 13: $275-280$

Roberts CM, Andelman S, Branch G, Bustamante RH and 10 others (2002a) Ecological criteria for evaluating candidate sites for marine reserves. Ecol Appl (in press)

Roberts CM, Branch G, Bustamante RH, Castilla JC and 8 others (2002b) Application of ecological criteria in selecting marine reserves and developing reserve networks. Ecol Appl (in press)

Schlacher TA, Newell P, Clavier J, Schlacher-Hoenlinger MA, Chevillon C, Britton J (1998) Soft-sediment benthic community structure in a coral reef lagoon-the prominence of spatial heterogeneity and 'spot endemism'. Mar Ecol Prog Ser 174:159-174

Sheppard CRC, Price ARG, Roberts CM (1992) Marine ecology of the Arabian region: patterns and processes in extreme tropical environments. Academic Press, London

Sheppard CRC (2000) Coral reefs of the western Indian Ocean: an overview. In: McClanahan TR, Sheppard CRC, Obura DO (eds) Coral reefs of the Indian Ocean: their ecology and conservation. Oxford University Press, Oxford, p 3-38

Sherman K, Duda AM (1999) An ecosystem approach to global assessment and management of coastal waters. Mar Ecol Prog Ser 190:271-287

Spalding MD (1999) Biodiversity patterns in Chagos reef fishes. Linn Soc Occas Pap 2:120-136

Tunnicliffe VJ (1992) Hydrothermal communities of the deep sea. Am Sci 80:336-349

Ward JH (1963) Hierarchical groupings to optimize an objective function. J Am Stat Assoc 58:236-246

Warwick RM, Clarke KR (1998) Taxonomic distictness and environmental assessment. J Appl Ecol 35:532-543

Warwick RM, Clarke KR (2001) Practical measures of marine biodiversity based on relatedness of species. Oceanogr Mar Biol Annu Rev 39:207-231

Williams P (2001) Complementarity. In: Levin SA (ed) Encyclopedia of biodiversity, Vol 1. Academic Press, London, p 813-829

Williams P, Gibbons D, Margules C, Rebelo A, Humphries C, Pressey R (1996) A comparison of richness hotspots, rarity hotspots, and complementary areas for conserving diversity of British birds. Conserv Biol 10:155-174

Submitted: December 20, 2001; Accepted: May 2, 2002

Proofs received from author(s): September 19, 2002 